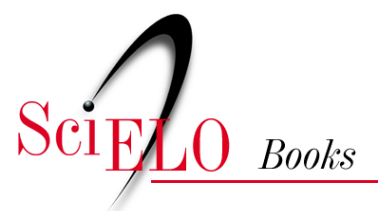

\title{
5. Orçamento público e fundos dos direitos da criança e do adolescente
}

\author{
Francisco Sadeck
}

\section{SciELO Books / SciELO Livros / SciELO Libros}

SADECK, F. Orçamento público e fundos dos direitos da criança e do adolescente. In: ASSIS, S.G., et al., orgs. Teoria e prática dos conselhos tutelares e conselhos dos direitos da criança e do adolescente [online]. Rio de Janeiro: Editora FIOCRUZ; Educação a Distância da Escola Nacional de Saúde Pública Sergio Arouca, 2009, pp. 255-286. ISBN: 978-85-7541-596-2. Available from: doi: 10.7476/9788575415962.0007. Also available in ePUB from: http://books.scielo.org/id/3svc2/epub/assis-9788575415962.epub.

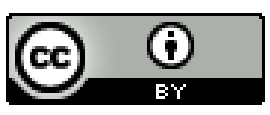

All the contents of this work, except where otherwise noted, is licensed under a Creative Commons Attribution $\underline{4.0 \text { International license. }}$

Todo o conteúdo deste trabalho, exceto quando houver ressalva, é publicado sob a licença Creative Commons Atribição 4.0. 


\section{Orçamento público e fundos dos direitos da criança e do adolescente}

Francisco Sadeck

Neste capítulo, refletimos sobre o financiamento de políticas sociais voltadas para crianças e adolescentes. Discutimos sobre orçamento público e o Fundo dos Direitos da Criança e do Adolescente (FDCA) para que você, conselheiro tutelar ou dos direitos, tenha acesso a instrumentos que o ajude em sua tarefa de defesa dos direitos da criança e do adolescente.

De acordo com a Constituição de 1988 (BRASIL, 1988), esse financiamento deve ser compartilhado entre a União, os estados, o Distrito Federal e os municípios. No entanto, há grandes desafios para a consolidação do modelo proposto na legislação. Em primeiro lugar, o financiamento compartilhado deve ser pautado por planejamentos integrados, que indiquem as ações prioritárias e os resultados a serem alcançados em um determinado intervalo de tempo. Infelizmente, as iniciativas de planejamento ainda são isoladas e, por vezes, não utilizadas como referência para a definição da partilha dos recursos das políticas sociais.

Outra questão relacionada ao financiamento é a de que, na composição do custo de uma ação, devem estar previstos recursos da União, do estado e do município. Isso raramente acontece; é mais comum observarmos ações sobrepostas do que propriamente um equilíbrio de financiamento.

Outro aspecto importante em relação ao financiamento de políticas sociais diz respeito aos fundos específicos. Os fundos são instrumentos de democratização do financiamento dessas políticas, uma vez que a destinação dos seus recursos requer aprovação do conselho, cuja 
composição é paritária. Assim, a sociedade civil e o governo definem a destinação dos recursos alocados nos fundos hoje existentes, possibilitando uma maior transparência no planejamento e na execução financeira.

Para monitorar o financiamento das políticas sociais, o conselho dos direitos de crianças e adolescentes precisa conhecer o orçamento destinado a cada área, distinguindo os valores reservados para transferência intergovernamental e os valores destinados do próprio orçamento. No caso da atenção aos direitos de crianças e adolescentes, essa tarefa requer o conhecimento de diversas políticas setoriais e a articulação com os conselhos que controlam essas políticas.

Os conselhos tutelares, por sua vez, devem conhecer a realidade local para influenciar na destinação dos recursos para execução das políticas sociais públicas. Esse papel é fundamental para garantir que os direitos de crianças e adolescentes sejam cumpridos e priorizados pelo Poder Público e, para tanto, é fundamental a articulação do conselho tutelar com o conselho dos direitos.

\section{Orçamento público}

O orçamento público tem tudo a ver com o nosso dia-a-dia. Grande parte das receitas governamentais, ou seja, do dinheiro que o governo arrecada, sai do nosso bolso, direta ou indiretamente. Quando compramos pãezinhos ou arroz, pagamos a conta da luz ou da água, por exemplo, repassamos uma parcela do que ganhamos para o governo, em forma de impostos indiretos, embutidos no preço das mercadorias e das tarifas dos serviços públicos. Há também impostos diretos, como o imposto de renda, pago por milhões de pessoas quando recebem o salário mensal ou quando prestam serviços para alguma empresa, ou para outra pessoa.

É com o dinheiro que esperam receber dos tributos (impostos, taxas e contribuições) que os governantes estimam e definem seus gastos todos os anos. Uma parte dos recursos é gasta em nosso benefício, uma vez que somos usuários dos serviços prestados e das obras construídas pelo governo, seja a canalização de um córrego na periferia, seja a modernização de um aeroporto, a abertura de novas vagas na creche do bairro, ou a contratação de mais atendentes para os postos do Instituto Nacional do Seguro Social (INSS), do Ministério da Previdência Social. 
A importância do orçamento público não é apenas econômica, mas principalmente política e social; é por meio dele que são decididas quais obras serão prioritárias, qual promessa de campanha será cumprida e qual reivindicação popular será atendida.

Para os conselhos dos direitos e tutelares a responsabilidade é ainda maior do que para o resto da população. Com base no orçamento, os conselheiros podem atuar para garantir recursos e priorizar políticas destinadas a crianças e adolescentes.

A atuação nas discussões acerca do orçamento público fortalece o papel dos conselhos dos direitos de acompanhar, avaliar e monitorar as ações públicas de promoção e defesa dos direitos de crianças e adolescentes, e o dos conselhos tutelares de zelar pelo cumprimento dos direitos, de acordo com a resolução 113 do Conanda.

\section{Para pensar}

Relembrando o caso do André, morador do município de Santana do Grajaú, apresentado no Capítulo 2, responda:

Como a atuação qualificada dos conselhos sobre o orçamento público poderia garantir material pedagógico especial para o menino?

De que modo o conselho poderia ajudar a promover políticas educacionais de qualidade para crianças e adolescentes com necessidades diversas?

Após ampla negociação, o orçamento público se transforma em um conjunto de documentos legais em que os governos (federal, estadual e municipal) deixam claro como pretendem gastar os recursos arrecadados com os impostos, contribuições sociais e outras fontes de receita, pagos pela população.

A elaboração do orçamento é obrigatória. Todos os anos os chefes do Poder Executivo (prefeitos, governadores e presidente da República) devem fazer a proposta de orçamento e enviá-la para discussão e votação na Câmara Municipal, no caso do município, na Assembléia Legislativa, no âmbito do estado, e no Congresso Nacional, quando se tratar da União. O resultado dessa discussão é a votação de uma lei - a Lei Orçamentária -, que autoriza o Executivo a gastar os recursos arrecadados para manter a administração, pagar os credores e fazer investimentos. 
Na lei do orçamento são estimadas todas as receitas e fixadas as despesas para o ano seguinte.

O orçamento demonstra o programa de trabalho de toda a administração pública. Tudo aquilo que o governo poderá gastar deve estar descrito na lei orçamentária: salário dos funcionários públicos, pagamento de dívidas, pensões e aposentadorias, programas sociais etc.

Figura 1 - Lei orçamentária

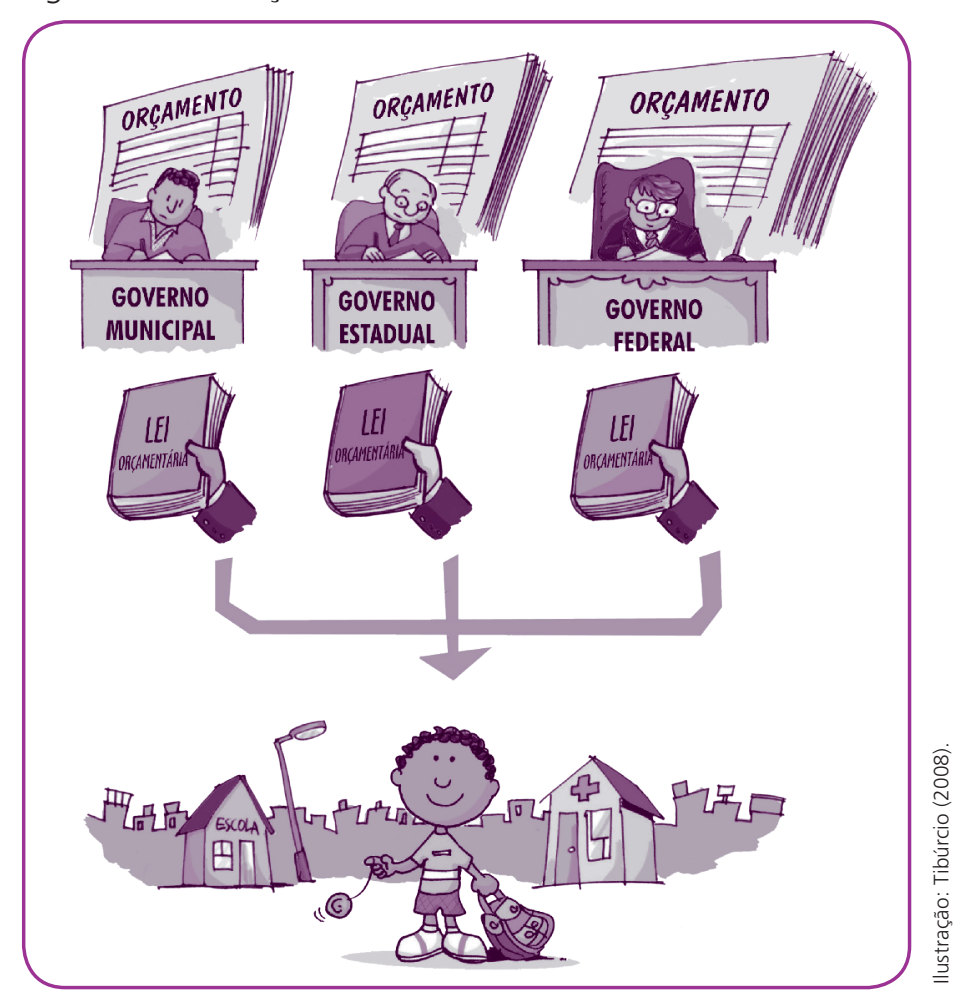

Os gastos não previstos não poderão ser realizados. Nenhum governo pode construir uma escola ou um centro esportivo, ajudar famílias carentes ou aumentar o salário dos professores, por exemplo, se não estiver autorizado pelo orçamento a aplicar recursos em ações dessa natureza.

\section{Para pensar}

Você sabe como é elaborado o orçamento no seu estado/município? Você participa da sua elaboração?

Procure a secretaria a qual o conselho está ligado e informe-se sobre os prazos e possíveis formas de participação. 
Os conselhos dos direitos e tutelares exercem importante papel na fiscalização do orçamento público, verificando se as suas funções estão sendo cumpridas. A seguir, descrevemos as principais funções e características do orçamento público:

- Decisão política - algumas pessoas querem mais creches, mais universidades e melhores salários para os professores. Outras desejam transporte escolar passando perto de casa, mais espaços de lazer e postos de saúde. Muitas querem criar empregos e baratear o preço dos remédios. Para outras, é prioritário reduzir impostos e investir na área social. Ou seja, os interesses são diferentes e até conflitantes. Ao elaborar o orçamento, os governantes fazem escolhas políticas, definindo as prioridades de governo, que vão muito além de questões sociais. As decisões envolvem grupos de interesse com os quais os governantes têm compromissos dentro e fora do país. Por isso, os conselheiros dos direitos e tutelares devem ficar atentos às decisões sobre o destino dos recursos públicos, intervindo no processo orçamentário para defender as propostas de garantia dos direitos das crianças e dos adolescentes do seu município.

\section{Para pensar}

Quais são as políticas prioritárias para a infância e a adolescência no seu município? Elas são contempladas no orçamento?

- Planejamento - o orçamento é um programa de trabalho, com metas e objetivos a serem alcançados. Ao elaborar o orçamento, o governo faz uma estimativa de arrecadação e de gastos para garantir, entre outras coisas, que os serviços e as obras em andamento tenham continuidade ao longo do ano e que não haja cortes repentinos em programas sociais ou atrasos no pagamento de aposentados e pensionistas, por exemplo.

- Distribuição de renda - o orçamento público funciona como redistribuidor de renda, quando tira recursos de vários setores da sociedade e os aplica em outros, para gerar desenvolvimento, criar empregos, combater a pobreza e tornar o país menos injusto socialmente. Essa escolha política depende muito da organização e da pressão da sociedade e dos conselhos, uma vez que melhorar a distribuição de renda e garantir a justiça social significa, em muitos casos, contrariar interesses de grupos e setores poderosos. Quando o governo decide aplicar uma fatia maior dos recursos em benefício de apenas uma parcela da sociedade, dizemos que o gasto está sendo focalizado. Mas se toda a população pode ser potencialmente beneficiada pelos gastos públicos, então o gasto é universal. O gasto com educação, por exemplo, é universal. Todas as pessoas, ricas e pobres, podem ter acesso à educação pública. 
- Democracia - em um regime democrático, nenhum governante pode decidir sozinho de que forma gastar os recursos públicos ou optar, sozinho, pelo aumento de impostos para arrecadar mais e pôr em prática o plano de governo que divulgou na sua campanha eleitoral. Essas decisões envolvem o Executivo e o Legislativo; só depois que o orçamento for aprovado pelo Legislativo é que os órgãos e as entidades da administração pública poderão aplicar os recursos naquilo que foi previsto.

- Transparência governamental/controle social - o orçamento (municipal, estadual ou federal) é público. Todas as pessoas podem e devem ter acesso aos números e ao destino do dinheiro que os governantes arrecadam. Esse dinheiro pertence não a um grupo de pessoas, mas a todos nós. Além de conhecer o conteúdo do orçamento e de se organizar para participar de sua elaboração, os conselhos dos direitos e tutelares devem acompanhar a sua execução (a aplicação dos recursos), evitando o descumprimento da Lei Orçamentária, o desperdício e desvio de dinheiro público e garantindo a efetivação dos direitos de crianças e adolescentes. Isso é o que chamamos de controle social.

- Direito à informação - qualquer cidadão pode ter acesso aos dados orçamentários da União, do estado e do município. Na União, o Senado Federal disponibiliza as informações orçamentárias pelo sistema "Siga Brasil", via internet. Quando esses dados não estão disponíveis na internet ou em outros meios de informação, é preciso entrar em contato com a Secretaria Estadual ou Municipal de Planejamento (ou o órgão responsável pela elaboração do orçamento) para se informar sobre a modalidade de consulta. A Lei Complementar n. 101, de 4 de maio de 2000 (BRASIL, 2000), intitulada Lei de Responsabilidade Fiscal (LRF), garante esse direito. Muitas vezes é necessário fazer pressão política para se ter acesso às informações necessárias à participação e ao controle social. Esse direito é imprescindível para que haja a democratização do processo orçamentário; sem acesso à informação, torna-se impossível monitorar e controlar os gastos públicos.

\section{Para pensar}

Seu estado/município fornece acesso às informações orçamentárias? No caso de não conseguir acessá-las, você sabe que o Ministério Público pode ajudá-lo a obter os dados?

- Força de lei - apesar de ser uma lei, o orçamento é apenas autorizativo, ou seja, ele não obriga o governo a aplicar todos os recursos reservados para uma obra, um programa ou uma ação. Por causa desse caráter autorizativo, muitas vezes os chefes do Poder Executivo (prefeitos, governadores e o 
presidente) usam o orçamento como "moeda de troca", liberando verbas ou aprovando a execução de obras e atividades de interesse de vereadores, deputados estaduais e federais e senadores, em troca de apoio aos projetos governamentais. Ou seja, favorecendo a política da "compra de apoios", "troca de favores", que, na maioria das vezes, beneficia mais os políticos do que a população. Portanto, incluir uma reivindicação de obra no orçamento da sua cidade não é garantia de que essa obra sairá do papel. Espera-se que os conselhos dos direitos e tutelares se articulem e busquem meios de pressão política para que as políticas para a infância e adolescência sejam executadas.

O orçamento público obedece a um conjunto de normas chamado princípios orçamentários. Esses princípios estabelecem as regras gerais para a elaboração e o controle do orçamento da União, dos estados e municípios. Os conselhos dos direitos e tutelares devem atuar de modo a garantir o seu cumprimento. Desse modo, é favorecido o controle social, qualificada a ação dos conselhos no orçamento público e garantida a priorização de políticas para crianças e adolescentes.

Os princípios orçamentários são: unidade (cada cidade, cada estado ou a União tem um único orçamento); universalidade (todas as receitas e todas as despesas devem ser incluídas na Lei Orçamentária); anualidade (o orçamento público vigora por um período limitado de tempo); exclusividade (a Lei Orçamentária deve conter apenas matéria financeira); legalidade (para ter validade, o orçamento anual precisa se transformar em lei); equilíbrio (as despesas devem corresponder ao valor das receitas estimadas); publicidade (deve ter ampla divulgação para que o cidadão saiba como são empregados os recursos arrecadados por meio de impostos, contribuições e outras fontes de receita) e participação (gestão participativa/orçamento participativo, art. 44 da Lei n.10.257, de 10/07/2001) (BRASIL, 2001). A gestão participativa está no âmbito da competência municipal (BRASIL, 1988, art. 182), caracterizando um de seus instrumentos de execução da política de desenvolvimento urbano, em nível local. Nos âmbitos estadual e federal não é obrigatória a observância do princípio da gestão participativa.

No que se refere à publicidade, o orçamento do governo federal deve ser publicado no Diário Oficial da União, assim que for sancionado pelo presidente da República. Os orçamentos do Distrito Federal, dos estados

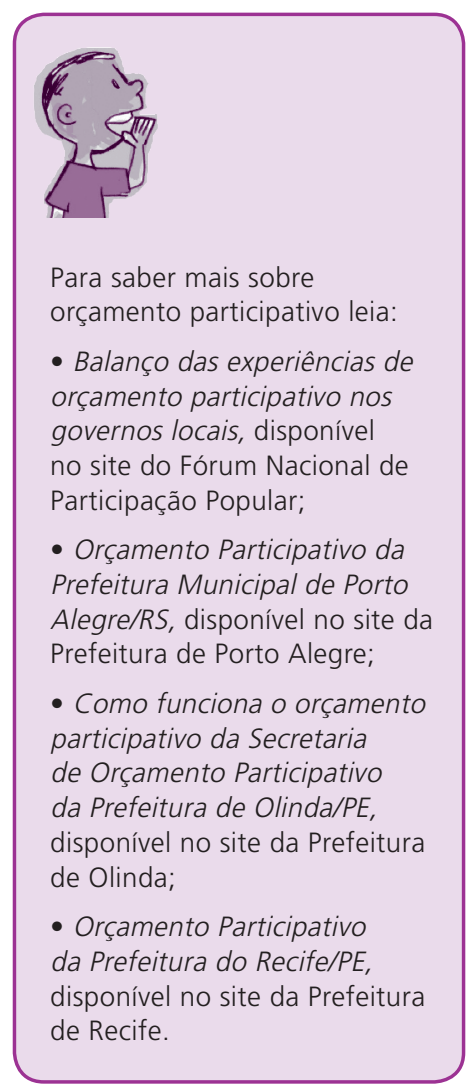


e dos municípios também devem ser publicados nos respectivos Diários Oficiais, ou em jornal de ampla circulação na cidade. Já aquelas prefeituras de cidades pequenas, que não possuem jornal próprio ou internet, podem afixar a Lei Orçamentária até na porta da prefeitura.

\section{Para pensar}

No seu município tem orçamento participativo? Como ele funciona?

Você considera o processo de participação popular no orçamento municipal eficaz no sentido de assegurar as demandas da sociedade?

Em todo orçamento público, há dois tipos de despesas previstas:

- Despesas obrigatórias - são aquelas previstas em lei. A maioria dos recursos já está comprometida com as despesas obrigatórias, como salários dos funcionários públicos, aposentadorias, pensões e benefícios da previdência social, funcionamento de escolas e hospitais, repasses obrigatórios para estados e municípios e, principalmente, refinanciamento, juros e a amortização das dívidas externa e interna. Algumas despesas com políticas sociais, como saúde, educação e previdência, constam na relação das despesas obrigatórias. Elas estão descritas na Constituição Federal e são resultado de muita luta dos movimentos sociais, da sociedade civil organizada. Assim, esses gastos, essenciais para garantir direitos básicos de cidadãos e cidadãs, não são condicionados às escolhas políticas dos governantes.

- Despesas discricionárias - são aquelas em que o governo pode aplicar os recursos como quiser. No entanto, com tantas despesas obrigatórias, sobra pouco para destinar às novas obras ou para aumentar o número de pessoas atendidas pelos programas sociais, por exemplo. O recurso que "sobra" para aplicar (menos de $1 / 4$ do orçamento federal, nos últimos anos) é motivo de muitas disputas entre interesses diversos. Ainda que não sejam obrigatórias, essas despesas devem ser debatidas, devem estar inseridas no Plano Plurianual (PPA), na Lei de Diretrizes Orçamentárias (LDO) e na Lei Orçamentária Anual (LOA), cabendo o mesmo processo de avaliação e prestação de contas. 


\section{Para pensar}

Em relação às despesas obrigatórias, você sabe os mínimos constitucionais de investimento em políticas sociais que seu estado/município deve cumprir? Esses mínimos estão sendo cumpridos?

De que forma, no seu município, os recursos estão sendo aplicados?

Conhecendo a realidade e as necessidades locais, em que ações os recursos seriam mais bem empregados?

\section{O ciclo orçamentário}

Três leis compõem o ciclo orçamentário:

- Plano Plurianual (PPA) - é o planejamento de longo prazo. Define as estratégias, diretrizes e metas do governo por um período de quatro anos. É elaborado no primeiro ano de mandato do prefeito, governador ou presidente e vigora até o primeiro ano de mandato do próximo governante, de forma a garantir a continuidade política e administrativa.

- Lei de Diretrizes Orçamentárias (LDO) - define as metas e as prioridades do governo, ou seja, as obras e serviços mais importantes a serem realizados no ano seguinte. Estabelece as regras que deverão ser observadas na formulação do Projeto de Lei Orçamentária Anual pelo Poder Executivo e na sua discussão, votação e aprovação, pelo Legislativo.

- Lei Orçamentária Anual (LOA) - nessa lei o governo demonstra todas as receitas e despesas para o ano seguinte. A LOA é composta de três esferas:

- orçamento da seguridade social - abrange todos os órgãos e entidades envolvidos nas ações relativas à saúde, previdência e assistência social;

- orçamento fiscal - abrange todos os outros órgãos e entidades não incluídos nos demais orçamentos;

- orçamento de investimento das empresas estatais - corresponde às despesas com obras e equipamentos. As demais despesas, como salário de funcionários e manutenção de atividades das estatais, não são previstas na Lei Orçamentária; elas estão incluídas apenas na contabilidade das próprias empresas estatais.

O papel das três leis (PPA, LDO e LOA) é integrar as atividades de planejamento e orçamento para assegurar o sucesso da ação governamental nos municípios, nos estados e no país.
Mínimos constitucionais são vinculações de recursos para as políticas públicas expressas na Constituição Federal. Por exemplo, na área de educação o art. 212 fala que a União aplicará no mínimo $18 \%$ do total da arrecadação, incluindo transferências. Para estados e municípios a aplicação é de pelo menos $25 \%$. 
Também chamado de ciclo integrado de planejamento e orçamento, o ciclo orçamentário corresponde a um período de quatro anos, que tem início com a elaboração do PPA e se encerra com o julgamento, pelo Poder Legislativo, da última prestação de contas do Poder Executivo.

O ciclo orçamentário é um processo dinâmico e contínuo, com várias etapas articuladas entre si, por meio das quais sucessivos orçamentos são discutidos, elaborados, aprovados, executados, avaliados e julgados.

Figura 2 - Ciclo orçamentário

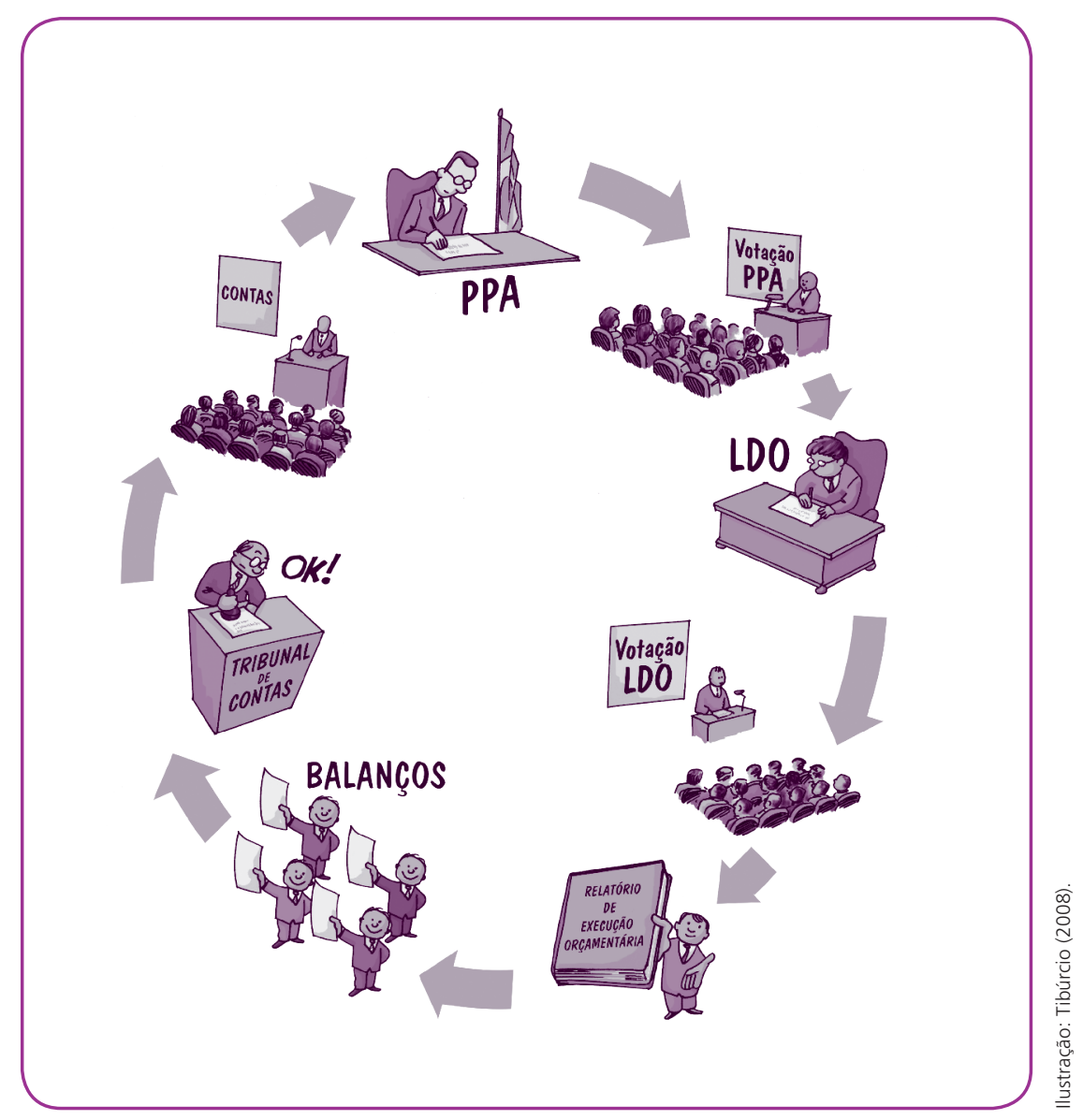

As três leis que regem o ciclo orçamentário são estreitamente ligadas entre si, compatíveis e harmônicas. Elas formam um sistema integrado de planejamento e orçamento, reconhecido na Constituição Federal, que deve ser adotado pelos municípios, pelos estados e pela União. 


\section{PASSO-A-PASSO DA ELABORAÇÃO E EXECUÇÃO DO ORÇAMENTO PÚBLICO}

1. 0 ciclo orçamentário tem início com a elaboração da proposta do PPA pelo Poder Executivo. Isso ocorre no primeiro ano de governo do presidente, governador ou prefeito recém-empossado ou reeleito.

2. Os membros do Legislativo discutem, apresentam emendas e votam o projeto de lei do PPA até o encerramento da sessão legislativa.

3. Com base no PPA, o Executivo formula a proposta da Lei de Diretrizes Orçamentárias, definindo prioridades e metas de governo. Os governantes recémempossados baseiam-se no PPA elaborado pelo governo anterior.

4. Os membros do Legislativo têm até o encerramento da primeira parte da sessão legislativa para examinar, modificar e votar o projeto da LDO. Do contrário, o recesso pode ser suspenso até que a LDO seja aprovada.

5. 0 Poder Executivo formula a proposta de Lei Orçamentária Anual de acordo com o PPA e a LDO. A elaboração da proposta orçamentária obedece às regras da LDO.

6. 0 Poder Legislativo deve examinar, modificar e votar o projeto de LOA até 0 encerramento da sessão legislativa. Caso contrário, o recesso é suspenso até que a votação seja concluída.

7. Os órgãos e entidades da administração pública executam seus orçamentos, estando sujeitos à fiscalização e ao controle interno do respectivo poder, bem como ao controle externo (Poder Legislativo com o auxílio do Tribunal de Contas).

8. Publicação do relatório de execução orçamentária, de acordo com a LRF - Lei Complementar n. 101, de 4 de maio de 2000 (BRASIL, 2000).

9. Conforme determina a Constituição Federal, 30 dias após o final de cada bimestre o Executivo deve divulgar um relatório resumido da execução orçamentária.

10. De acordo com determinações da LRF, os três poderes divulgam relatório de gestão fiscal trinta dias após o final de cada quadrimestre. Isso permite comparar a despesa com pessoal e o montante da dívida pública com os limites previstos na legislação.

11. Após o encerramento do exercício financeiro, o Executivo elabora os balanços e os demonstrativos contábeis gerais, de todos os órgãos e entidades da administração pública. Cada poder - Executivo, Legislativo e Judiciário - elabora sua prestação de contas separadamente.

12. 0 Executivo apresenta suas contas do ano anterior ao Legislativo, no máximo sessenta dias após a abertura da sessão legislativa.

13. 0 Tribunal de Contas emite parecer prévio sobre as contas do Executivo e dos demais poderes.

14. 0 Legislativo julga as contas apresentadas pelo Executivo. 
15. 0 Executivo divulga relatório de avaliação da execução PPA.

16. As etapas de três a quinze repetem-se por outros três anos consecutivos.

17. No quarto ano, o processo recomeça com a elaboração de um novo PPA.

As etapas do ciclo orçamentário são semelhantes na União, nos estados e nos municípios. As diferenças podem estar nas datas-limite de cada um deles. Os prazos dos estados são definidos na Constituição Estadual e no regimento interno da Assembléia Legislativa. Já os prazos dos municípios são estabelecidos na Lei Orgânica do Município e no Regimento Interno da Câmara Municipal.

\section{Para pensar}

Responda as indagações a seguir sobre a atuaçao dos conselhos dos direitos e tutelares no ciclo orçamentário do seu estado/município.

Os conselhos tutelares são chamados para ajudar na elaboração do orçamento, de acordo com o art. 136, inciso IX do ECA?

Os conselhos dos direitos e tutelares realizam articulações para incluir políticas de infância como prioridade na LDO, tanto no Executivo quanto no Legislativo? Você observa alguma articulação para assegurar e aumentar os recursos para políticas de infância na LOA, tanto no Executivo quanto no Legislativo? Como ela ocorre?

O que os conselhos dos direitos e tutelares podem fazer para garantir o controle social sobre os gastos públicos no seu estado/ município?

Tem havido situações de contingenciamento (ver definição mais adiante) de recursos do orçamento em sua localidade? Isto afetou as ações do conselho? Você tem acesso ao relatório de execução orçamentária e à prestação de contas? Qual o prazo para o Legislativo julgar a prestação de contas do Executivo?

\section{O processo orçamentário}

O processo orçamentário diz respeito ao papel de cada poder no orçamento público: como o orçamento é elaborado, discutido e aprovado e como a execução de suas ações é fiscalizada e avaliada. Cada poder tem papel específico nesse processo: ao Executivo cabe elaborar os projetos de lei e executá-los; ao Legislativo compete discutir, propor emendas, aprovar as 
propostas orçamentárias e julgar as contas apresentadas pelos chefes do Executivo - prefeitos, governadores e presidente da República.

Há órgãos encarregados da fiscalização e do julgamento das contas, como os Legislativos e os Tribunais de Contas. Os cidadãos também têm obrigações e direitos no processo orçamentário. É questão de se preparar para participar, expondo suas propostas e reivindicações.

Quatro etapas do processo orçamentário serão destacadas a seguir: a elaboração do projeto de lei, a etapa de discussão/votação do projeto de lei, a efetiva execução orçamentária e financeira e a avaliação e o controle das despesas realizadas.

A elaboração do projeto de lei do PPA, da LDO e da LOA cabe exclusivamente ao Executivo; em nenhuma esfera o Poder Legislativo pode propor tais leis. No âmbito municipal, por exemplo, apenas o prefeito pode apresentar à Câmara Municipal os projetos de PPA, LDO e LOA. Os vereadores não apresentam tais projetos, mas podem modificá-los por meio de emendas, quando enviados ao Legislativo para discussão e votação, como será visto no próximo ponto.

Ainda não há normas específicas para a elaboração do PPA e da LDO, pois a Constituição Federal, que criou esses instrumentos, determinou que as regras fossem fixadas em lei complementar. Até hoje, no entanto, tal lei não foi votada pelo Congresso Nacional. Ela substituirá a Lei n. 4.320, de 1964, que estabelece as normas para a elaboração da Lei Orçamentária Anual e execução orçamentária em todos os âmbitos governamentais: municipal, estadual e federal.

Geralmente, o processo de elaboração é dirigido pela Secretaria de Planejamento (Seplan), com base no levantamento enviado por todas as outras secretarias, que apontam as necessidades de gastos de cada área sob a sua responsabilidade. Cabe à Seplan compatibilizar a demanda por recursos com o total da receita que o governo espera arrecadar.

Ao elaborar a proposta, a Seplan leva em conta uma série de parâmetros, como expectativa de crescimento do PIB, média cambial, previsão de receita, metas de inflação e montante do refinanciamento da dívida pública. Os Poderes Legislativo e Judiciário também enviam suas propostas à Seplan para serem integradas ao orçamento geral. 
O chefe do Poder Executivo conta com uma equipe de assessoria política e técnica para definir a proposta de orçamento. É importante que essa assessoria conheça a realidade econômica e social do país, do estado ou do município. Ela precisa saber de onde vem a receita, como calcular a arrecadação e distribuir os recursos de acordo com as demandas de cada área e os objetivos e as metas governamentais.

Os conselhos dos direitos têm o papel de garantir que o seu plano de ação e as diretrizes e metas elencadas como prioritárias para as políticas sociais públicas, destinadas a crianças e adolescentes, sejam contempladas nas leis orçamentárias. Cabe aqui apresentar o exemplo do Conselho Nacional dos Direitos da Criança e do Adolescente (Conanda), que participou ativamente da discussão do PPA 2008-2011 do governo federal. O Conanda determinou as diretrizes das políticas para infância e a adolescência que deveriam ser incluídas no PPA, como a inclusão do Sinase, do Plano Nacional de Convivência Familiar e Comunitária, dentre outros.

VOCÊ SABIA QUE

- a inclusão do plano de ação dos conselhos municipais dos direitos no Plano Plurianual (PPA) dos municípios foi realizada por $78 \%$ dos conselhos, sendo, de maneira integral, em 29\%, e de maneira parcial, em $49 \%$ ?

- $22 \%$ dos conselhos não conseguiram levar, nem mesmo parcialmente, aspectos de seus planos de ação para o Poder Executivo Municipal?

- entre os conselhos estaduais dos direitos, $48 \%$ tiveram seus planos de ação parcialmente incluídos no orçamento estadual, $26 \%$ tiveram seus planos inseridos integralmente e os planos dos outros $26 \%$ não foram incluídos?

Fonte: Pesquisa nacional Ceats/FIA (2007), com dados de 2006, referentes a 49\% dos conselhos municipais e $96 \%$ dos conselhos estaduais de direitos.

O conselho estadual de Minas Gerais também conseguiu resultados positivos com a participação na elaboração do PPA estadual, chamado de Plano Plurianual de Ação Governamental (PPAG). Desta forma, houve a priorização da criança e do adolescente na agenda governamental refletida em recursos e políticas públicas. 


\section{Para pensar}

Como ocorre o processo de elaboração do orçamento pelo Executivo no seu estado/município?

O seu conselho tutelar participa junto ao Poder Público na definição de metas e políticas para a infância e adolescência?

O conselho dos direitos tem determinação nas políticas públicas para a infância no seu estado/município?

Em relação à discussão e votação do orçamento, a Constituição Federal determina que as propostas de PPA, LDO e LOA sejam analisadas, discutidas e votadas pelo Congresso Nacional, no caso da União, pela Assembléia Legislativa, na esfera dos estados e pela Câmara Municipal, no âmbito dos municípios. Em todas as casas do Legislativo, a proposta é primeiramente analisada por uma comissão de parlamentares e, depois, apreciada por todo o plenário.

Os parlamentares podem apresentar emendas, individual ou coletivamente, ao projeto original. No caso da LOA, podem, por exemplo, modificar a alocação de recursos e alterar a dotação orçamentária prevista para cada órgão ou entidade pública. No entanto, qualquer alteração precisa obedecer a algumas regras, entre as quais: não aumentar o total de despesas previsto no orçamento; ao incluir nova despesa ou aumentar despesa já prevista, indicar os recursos a serem cancelados de outra programação para cobrir o novo gasto; ser compatível com as disposições do PPA e da LDO; respeitar os limites de valor para as emendas individuais; e não cancelar despesas com pessoal, benefícios da previdência, transferências constitucionais, juros e amortização da dívida pública.

Após a aprovação do Legislativo, a proposta volta ao Executivo para sanção ou veto às emendas incluídas pelos parlamentares. O veto é apreciado pelo Legislativo, podendo ser aprovado ou derrubado.

O processo de articulação dos conselhos dos direitos e tutelares para a participação na elaboração da LOA terá mais consistência e efetividade se for iniciado desde as discussões preliminares da elaboração do PPA e da LDO. Porém, se não houver esta oportunidade de interlocução, ainda há a possibilidade de articulação direta junto ao Legislativo, por meio da apresentação de emendas ao orçamento, antes da votação da LOA. 
Essa prática normalmente resulta enorme ganho social, uma vez que possibilita a alocação de recursos para a garantia e efetivação dos direitos de crianças e adolescentes. Além disso, evita que a decisão sobre o que é ou não prioritário fique apenas nas mãos do Poder Executivo.

Figura 3 - Emendas ao orçamento

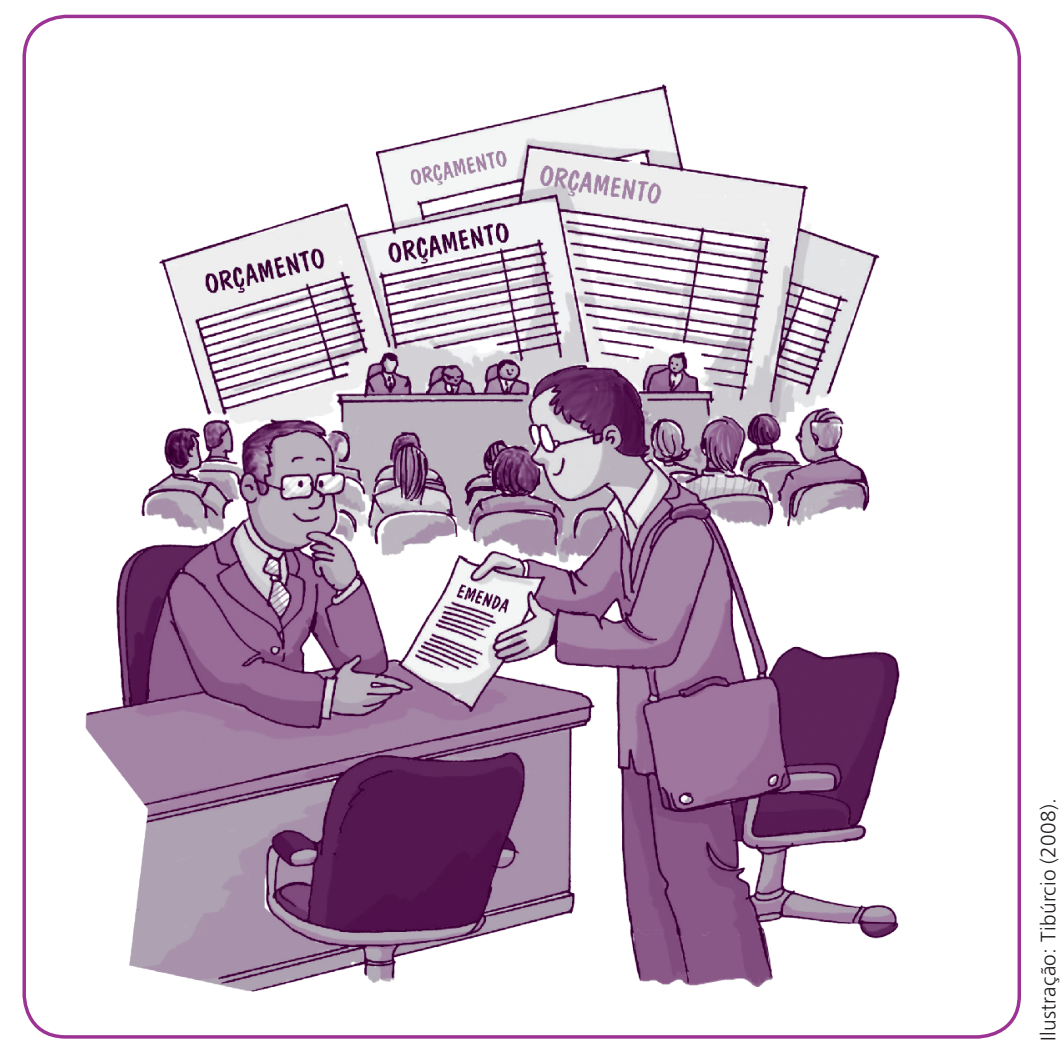

Em relação ao orçamento de 2007, votado em 2006, o Conanda articulou com organizações da sociedade civil e a Frente Parlamentar da Criança e do Adolescente, do Congresso Nacional, a apresentação de uma emenda de 1 bilhão de reais para garantir o atendimento das creches pelo Fundo da Educação Básica (Fundeb). Até então, a Proposta de Emenda à Constituição (PEC) do Fundeb passava por discussões para inclusão das creches no texto da lei. O Conanda percebeu, no entanto, que sem recursos não seria possível atendê-las, ainda que fossem contempladas no texto da lei. Com esse importante passo na alocação de recursos, as creches puderam fazer parte do Fundeb, inclusive com previsão de recursos. 


\section{Para pensar}

Há algum canal de participação da sociedade no orçamento do seu estado/ município?

Existe alguma iniciativa/parceria dos conselhos tutelares e dos direitos com o Legislativo local?

Há uma frente parlamentar da infância e adolescência no Legislativo de seu município?

No que concerne à aprovação do orçamento, nem sempre o Poder Legislativo consegue apreciar e votar o projeto enviado pelo Executivo dentro do prazo constitucional - o encerramento da sessão legislativa. Em todas as esferas de governo, o Legislativo não entra em recesso até a aprovação do orçamento. No entanto, a Constituição Federal não diz o que acontecerá se a lei não for sancionada até o dia 31 de dezembro (como sabemos, a LOA deve entrar em vigor em $1^{\circ}$ de janeiro). Por isso, diversas Leis de Diretrizes Orçamentárias (LDO) têm estabelecido regras para a execução provisória do orçamento até que este seja votado e sancionado.

Algumas LDOs autorizam a utilização provisória dos recursos de forma genérica, normalmente um duodécimo (1/12) do total do orçamento por mês até a aprovação da LOA. Outras, mais rígidas, autorizam a execução orçamentária apenas para atender alguns tipos de despesas consideradas inadiáveis, como transferências constitucionais, pagamento de pessoal e de juros e encargos de dívidas.

Enquanto o orçamento não for votado em seu município, o prefeito não poderá, por exemplo, iniciar uma nova obra como o calçamento das ruas de um bairro da periferia, mesmo que os recursos fiquem "parados" no caixa da prefeitura. Por isso, é importante acompanhar de perto o processo de discussão e votação da Lei Orçamentária. Além de defender os interesses da coletividade, a participação popular pode contribuir para que o orçamento seja votado dentro do prazo e garantir recursos para políticas consideradas prioritárias.

Sobre a execução orçamentária e financeira, depois que a LOA é publicada no Diário Oficial e passa a valer, os órgãos e entidades da administração pública começam a executar o orçamento, ou seja, passam a 
realizar as atividades programadas e a aplicar o dinheiro de suas dotações orçamentárias.

Até trinta dias após a publicação da LOA, o Executivo estabelece o cronograma mensal de desembolso e a programação financeira, de acordo com as determinações da Lei de Responsabilidade Fiscal (LRF). Entre outras determinações, a LRF fixa limites para despesas com pessoal e para a dívida pública, além de proibir a criação de despesas de duração continuada (mais de dois anos), sem que haja uma fonte segura de receitas. É o respaldo jurídico ao modelo econômico hoje vigente no país. Seu conteúdo é dirigido ao ajuste das contas da União, dos estados e municípios.

Com a criação do cronograma mensal de desembolso, o governo ajusta o ritmo de execução do orçamento ao fluxo dos recursos, mantém o equilíbrio entre receita e despesa e garante verba, em tempo hábil, às unidades administrativas, visando melhorar a execução do seu programa de trabalho.

Os órgãos e entidades da administração pública devem seguir à risca o que está determinado na lei, não gastando nada além do estipulado para cada programa ou atividade. Muitas vezes, no meio do caminho, o governo reavalia a estimativa de receita e reduz o limite autorizado de despesas para cumprir a meta fiscal (o quanto se espera gastar a menos do que o total arrecadado), ou aumenta a autorização para a despesa, mediante excesso de arrecadação.

A cada dois meses, o Executivo reavalia as estimativas de receitas e despesas, para verificar se a meta fiscal será cumprida. Se necessário, para cumprir a meta, os Poderes Legislativo, Executivo e Judiciário reduzem temporariamente os limites para a realização de despesas. Esta redução é chamada de "contingenciamento".

O conselho dos direitos pode solicitar ao Poder Executivo relatórios periódicos da execução orçamentária. De posse dessas informações, é possível analisar a liberação dos recursos e propor alterações/adequações necessárias ao atendimento das necessidades de crianças e adolescentes, inclusive alterar prioridades no decorrer do ano. Os conselhos tutelares, por sua vez, podem ser importantes parceiros na análise da execução 
orçamentária, indicando quais alterações possíveis devem ser feitas, de modo a contemplar a realidade social do município.

\section{Para pensar}

Você tem acesso às informações sobre a execução orçamentária do seu estado/município?

Sabe quanto o governo gasta em políticas para a infância e a adolescência?

O conselho dos direitos solicita/recebe periodicamente relatórios sobre orçamento das políticas para infância e a adolescência?

Para avaliação e controle do orçamento, após o encerramento de cada exercício, o chefe do Executivo deve apresentar um balanço geral das receitas arrecadadas e das ações e despesas executadas ao longo do ano. Essa prestação de contas é analisada pelo Legislativo e pelo Tribunal de Contas da União, do estado ou do município.

Os órgãos e entidades que executam os orçamentos estão sujeitos à fiscalização por órgãos internos e externos. Eles devem prestar contas de suas realizações e gastos, periodicamente. A prestação de contas deve ser pública, acessível a todo e qualquer cidadão e não apenas aos órgãos de fiscalização e controle do próprio governo. Além disso, é disponibilizada pela Seplan (ou outra instituição responsável pelo orçamento no seu município), pelo Legislativo ou Tribunal de Contas.

Vale ressaltar que os controles - oficial e social - ocorrem quando o orçamento está em execução. O controle interno é feito pelos órgãos da administração direta - no caso da União, os Ministérios e a Controladoria Geral. O controle externo é feito pelo Legislativo, com o auxílio do Tribunal de Contas.

No controle social, realizado pela sociedade e pelos conselhos dos direitos e tutelares, um importante parceiro é o Ministério Público (MP). O MP não discute, não vota nem aprova o orçamento. Porém, é chamado para intervir legal e penalmente quando qualquer irregularidade é constatada pelos órgãos de controle social, interno ou externo. Ele age, portanto, como um fiscal da lei. Se determinada lei não está sendo cumprida, ou está sendo aplicada de maneira equivocada, o MP possui mecanismos para impor a sua correta aplicação. 
No caso da evasão escolar, descrito no Capítulo 2, o MP atuou por meio de um Termo de Ajustamento de Conduta (TAC). A prefeita de Santana do Grajaú foi então obrigada a fazer alterações no orçamento para que o direito de estudar fosse assegurado ao menino André. Outra possível atuação do MP é a ação civil pública, que é aplicada para a defesa de interesses difusos, coletivos e individuais homogêneos.

A parceria entre os conselhos dos direitos e o MP tende a gerar muitos resultados. Na $6^{a}$ Conferência Nacional da Criança e do Adolescente, realizada em 2005, em Brasília, em virtude da pressão exercida pelos conselheiros da sociedade civil, o MP ameaçou entrar com uma ação civil pública para garantir o descontingenciamento dos recursos federais da área da infância, a cargo da Secretaria Especial dos Direitos Humanos (SEDH). O entendimento era o de que o contingenciamento feria o disposto no art. $4^{\circ}$, parágrafo único, alínea d do ECA, visto que os recursos não estavam sendo aplicados privilegiadamente em políticas destinadas a crianças e adolescentes.

Com a ameaça do MP de entrar com a ação civil pública, os conselheiros governamentais articularam junto à Presidência da República e ao Ministério do Planejamento a liberação dos recursos em questão. Eles foram disponibilizados ainda durante a realização da conferência, não havendo necessidade de entrar com o aparato jurídico da ação civil pública.

\section{Orçamento criança e adolescente}

O Orçamento Criança e Adolescente (OCA) indica quais políticas públicas destinadas a crianças e adolescentes compõem o orçamento público. Existem várias metodologias de apuração e análise do OCA.

O projeto de monitoramento dos gastos do OCA tem por base legal o art. 227 da Constituição Federal de 1988 e o art. $4^{\circ}$ do Estatuto da Criança e do Adolescente (BRASIL, 1990). O OCA também atende ao art. $4^{\circ}$ da Convenção Internacional sobre os Direitos das Crianças.

O objetivo do OCA é verificar se a prioridade absoluta da criança e do adolescente, na agenda governamental, está sendo cumprida. De posse das informações orçamentárias, é possível influenciar o processo orçamentário, monitorando e dando visibilidade à execução do OCA, 
subsidiando estratégias de fortalecimento do sistema de garantia dos direitos da criança e do adolescente e da luta pela implementação de políticas públicas que respondam às metas prioritárias para essa população.

É extremamente importante a participação dos conselhos dos direitos no processo de elaboração das leis orçamentárias, no Executivo, e nas discussões realizadas no Legislativo. Os conselheiros têm que ficar atentos aos prazos para inserir suas demandas políticas e necessidades na agenda governamental.

As ações de monitoramento do gasto público fortalecem o controle social, capaz de identificar desvios, não cumprimento das prioridades e responsabilização na execução dos gastos. Constatadas irregularidades, os conselhos dos direitos e tutelares podem buscar parceiros como o Ministério Público e o Tribunal de Contas para investigar as denúncias e responsabilizar o Poder Público. A atuação dos conselhos sobre o orçamento público garante que as políticas sejam aplicadas de forma efetiva na garantia dos direitos de crianças e adolescentes.

\section{Fundo dos Direitos da Criança e do Adolescente}

Embora o Fundo esteja diretamente vinculado ao conselho dos direitos, sublinhamos a importância dos conselheiros tutelares conhecerem as principais características envolvidas na aplicação e fiscalização dos recursos dirigidos a crianças e adolescentes.

O Fundo dos Direitos da Criança e do Adolescente (FDCA) é um fundo público, de modalidade especial, instituído pela Lei n. 8.069/90 (BRASIL, 1990) e pela Lei Federal n. 8.242/91 (BRASIL, 1991). É também conhecido como FIA ou simplesmente como Fundo da Criança e do Adolescente. Na União, nos estados, no Distrito Federal e nos municípios deverá ser criado um único e respectivo Fundo, conforme estabelece o ECA (BRASIL, 1990, art. 88, IV).

A compreensão do Fundo da Criança e do Adolescente passa pelo entendimento do lugar que ele ocupa no orçamento público. É um fundo
Os fundos especiais foram criados com o objetivo de democratizar e dar maior transparência ao trato com o dinheiro público, por meio do controle social. 
especial regido pelos art. 71 a 74 da Lei n. 4.320, de 17 de março de 1964 (BRASIL, 1964), que dispõe sobre as normas gerais para a elaboração e controle do orçamento:

art. 71 - Constitui fundo especial o produto de receitas especificadas que por lei se vinculam à realização de determinados objetivos ou serviços, facultada a adoção de normas peculiares de aplicação.

art. 72 - A aplicação das receitas orçamentárias vinculadas a fundos especiais far-se-á através de dotação consignada na Lei de Orçamento ou em créditos adicionais.

art. 73 - Salvo determinação em contrário da lei que o instituiu, o saldo positivo do fundo especial apurado em balanço será transferido para o exercício seguinte, a crédito do mesmo fundo.

art. 74 - A lei que instituir fundo especial poderá determinar normas peculiares de controle, prestação e tomada de contas, sem, de qualquer modo, elidir a competência específica do Tribunal de Contas ou órgão equivalente.

Os artigos transcritos determinam que os fundos especiais sejam compostos por recursos destinados exclusivamente a serviços e objetivos especificados em suas leis de criação. Os Fundos da Criança e do Adolescente têm suas receitas vinculadas a programas e projetos destinados à garantia dos direitos dessa população, de acordo com o art. 227 da Constituição Federal (BRASIL, 1988) e o ECA (BRASIL, 1990).

O Fundo da Criança e do Adolescente obedece ao disposto no art. 204 da Constituição Federal de 1988:

art. 204 - As ações governamentais na área da assistência social serão realizadas com recursos do orçamento da seguridade social, previstos no art. 195, além de outras fontes, e organizadas com base nas seguintes diretrizes:

I. descentralização político-administrativa, cabendo a coordenação e as normas gerais à esfera federal e a coordenação e execução dos respectivos programas, às esferas estadual e municipal, bem como a entidades beneficentes e de assistência social;

II. participação da população, por meio de organizações representativas, na formulação das políticas e no controle das ações em todos os níveis (BRASIL, 1988).

O art. 204 dispõe sobre a democracia participativa no campo orçamentário, o que representa uma importante vitória da luta dos movimentos sociais que, durante as décadas anteriores, reivindicavam a essa inclusão no processo decisório das políticas públicas. A gestão da política social 
para crianças e adolescentes, por meio de um fundo vinculado ao conselho paritário, garante maior transparência e visibilidade na utilização dos recursos públicos.

\section{Para pensar}

No seu município existe um Fundo dos Direitos da Criança e do Adolescente? Como ele é chamado?

A transparência no gasto público é uma das linhas de ação do conselho dos direitos em seu município? O Poder Público presta contas à sociedade e emite relatórios dos recursos que aplica nas políticas para a infância?

O Fundo dos Direitos da Criança e do Adolescente pressupõe a partilha de poder na definição das prioridades do orçamento na área da infância. Em geral, ele é atrelado à Secretaria de Assistência Social e, em alguns casos, também são envolvidas as Secretarias de Finanças ou Planejamento.

O ECA prevê a criação do FDCA nas três esferas da federação, a fim de agregar os recursos financeiros necessários à instalação e manutenção da rede de proteção. Os fundos são criados como uma das diretrizes da política de atendimento à criança e ao adolescente. Ressaltamos que o FDCA não responde pela totalidade da política para crianças e adolescentes, é apenas parte do todo!

Os fundos especiais devem ser criados por meio de um projeto de lei de autoria do Poder Executivo, encaminhado para votação no Legislativo e, sendo aprovado, de um decreto que o regulamente. A lei deve determinar o órgão estatal ao qual ele será vinculado, suas receitas e despesas, bem como os responsáveis por sua gestão.

A ausência de uma regulamentação nacional do FDCA faz com que os diversos fundos no país funcionem de acordo com as leis que os criaram. Não há uma unidade conceitual entre as diversas leis, o que dificulta o relacionamento dos conselhos deliberativos com alguns setores do Poder Público, bem como a troca de experiências entre os diversos conselhos dos direitos. Percebendo essa lacuna, o Conanda está trabalhando em um documento de parâmetros para a criação e funcionamento dos fundos nacional, estaduais, distritais e municipais dos direitos da criança e do adolescente.
O Fundo é uma das condições fundamentais para a realização dos princípios e diretrizes do ECA. Não existe prioridade absoluta sem prioridade orçamentária! 


\section{VOCÊ SABIA QUE}

O Fundo dos Direitos da Criança e do Adolescente é lei e está regulamentado em $71 \%$ dos conselhos analisados na pesquisa "Bons Conselhos" ? No entanto, ele está criado, mas não regulamentado, em $21 \%$ dos municípios, e em $8 \%$ ainda não chegou a ser criado.

Fonte: Pesquisa nacional Ceats/FIA (2007), com dados de 2006, referentes a 49\% dos conselhos municipais e $96 \%$ dos conselhos estaduais dos direitos.

\section{O FDCA e as políticas para a infância}

O FDCA é o mecanismo instituído com a finalidade de assegurar recursos para programas e projetos de garantia dos direitos de crianças e adolescentes. Os programas devem estar atrelados às demais políticas destinadas a essa população, formando um arco de proteção, com base em um plano elaborado pelo conselho dos direitos.

O orçamento público deve financiar as políticas sociais básicas e assistenciais, garantindo a proteção integral. O Fundo Municipal reúne os recursos destinados à implementação de uma parte da política voltada à criança e ao adolescente, no caso, a dos programas complementares.

De acordo com o Estatuto, as políticas financiadas pelo Fundo serão implementadas por meio de um conjunto articulado de ações governamentais e não governamentais, seguindo os regimes de atendimento dispostos no art. 90, em projetos de proteção especial ou em situações especiais, referenciais ou emergenciais, tais como: enfrentamento da violência, atendimento a adolescentes em risco, orientação e apoio sociofamiliar, apoio socioeducativo em meio aberto, colocação familiar, abrigo, liberdade assistida, semiliberdade, internação, combate ao trabalho infantil, adequação das instalações físicas de instituições de atendimento infantil, capacitação de educadores e conselheiros e programas de guarda. 
Figura 4 - Políticas financiadas pelo Fundo dos Direitos da Criança e do Adolescente

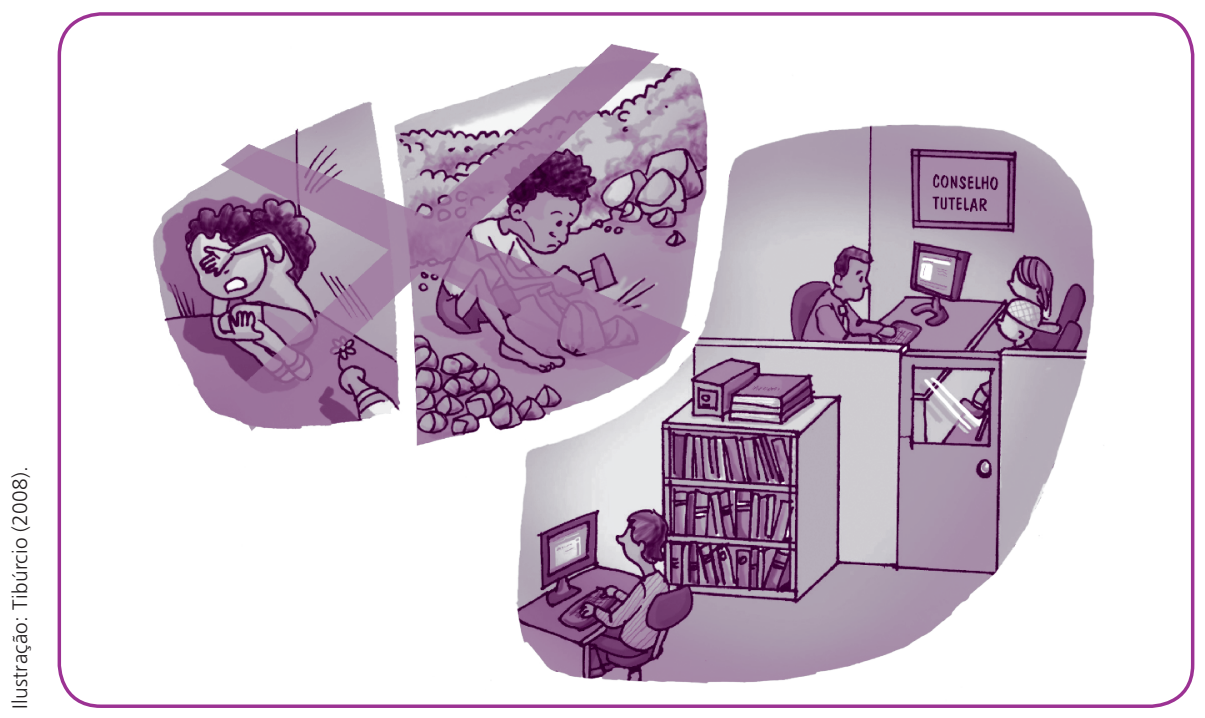

Outras ações também comumente financiadas pelo FDCA são: atendimento a toxicômanos, diagnóstico da realidade e divulgação do Estatuto da Criança e do Adolescente.

Os recursos do FDCA não devem ser utilizados para pagamento, manutenção e funcionamento do conselho tutelar; manutenção e funcionamento dos conselhos dos direitos da criança e do adolescente; em políticas públicas que já disponham de fundos específicos (como as de educação infantil, especial e de iniciação profissional de adolescentes); ou, ainda, para transferência de recursos sem a deliberação do respectivo conselho dos direitos, como parte da política pública específica.

Essas políticas devem ser implementadas, de forma descentralizada, por entidades de atendimento governamentais ou não governamentais, mediante inscrição de programas no conselho municipal dos direitos da criança e do adolescente.

As entidades selecionadas de acordo com as diretrizes do plano de aplicação elaborado pelo conselho firmam convênios necessários à realização do atendimento. Cada conselho municipal deve elaborar em seu regimento interno, e por meio de suas resoluções, os critérios específicos (prazos, linhas de atendimento etc.) para esse processo.
Vale lembrar que as entidades não governamentais só podem receber recursos do FDCA depois de registradas no conselho municipal dos direitos da criança e do adolescente. 
A lei de criação e o decreto de regulamentação do Fundo devem explicitar o que pode ser realizado com o seu financiamento. O pagamento de manutenção, infra-estrutura e remuneração do conselho tutelar deve ser feito pela própria Secretaria de Governo. Em alguns municípios, os conselhos tutelares são financiados com recursos do FDCA, mesmo sendo ilegal essa destinação.

\section{Para pensar}

Os recursos do FDCA são utilizados para o funcionamento dos conselhos dos direitos ou tutelares em seu município? Quais os programas complementares financiados com recursos do Fundo?

\section{Receitas do fundo da criança e do adolescente}

Os recursos que compõem os fundos da criança e do adolescente fazem parte do Tesouro Público. A sua principal fonte deve ser a dotação própria do Poder Público (município, estado, Distrito Federal e União), conforme estabelece o art. 227 da Constituição Federal (BRASIL, 1988) e a determinação do art. $4^{\circ}$, parágrafo único, alínea d do ECA (destinação privilegiada de recursos públicos para programas voltados ao atendimento de crianças e de adolescentes). Entretanto, as fontes desses recursos vão além do dinheiro público constante no orçamento. Também provêm de:

- destinações do imposto de renda de pessoas físicas ou jurídicas para os fundos nacional, estaduais ou municipais. De acordo com o art. 260 do ECA, a pessoa física pode destinar recursos para o FDCA e abater até $6 \%$ do Imposto de Renda devido; para a pessoa jurídica (empresas privadas ou estatais), o abatimento é de até 1\% (BRASIL, 1990);

- multas decorrentes de condenação em ações cíveis e aplicação de penalidades administrativas ou penais previstas nos art. 228 a 258 do ECA (BRASIL, 1990);

- outras fontes, tais como convênios, transferências entre entes da federação, doações/contribuições de pessoas físicas, governos, organismos nacionais ou internacionais, resultados de aplicações financeiras e de cláusulas específicas de contratos de licitação pública;

- doações de bens materiais de pessoas físicas ou jurídicas. 


\section{Para pensar}

É importante que o conselho faça a Declaração de Benefícios Fiscais (DBF) para a Receita Federal. Assim, evita que a pessoa que fez a destinação do Imposto de Renda para o Fundo dos Direitos caia na malha fina.

O conselho do seu município procede desse modo ao receber destinações do Imposto de Renda? Envia recibo de destinação para o Fundo às pessoas físicas ou jurídicas? Presta contas da receita, dá informações ou emite relatórios para quem faz a destinação, informando como os recursos foram aplicados?

No caso do FDCA, a legislação não faz referência a transferências de fundo a fundo, como, por exemplo, no caso da assistência social. Uma vez que a legislação nada informa sobre a questão, esse tipo de transferência não acontece de maneira permanente e institucionalizada. Sabe-se que alguns conselhos dos direitos, como o de São Paulo, adotam transferências fundo a fundo do FDCA estadual para o municipal.

Esse tipo de transferência também ocorre no seu município?

\section{Gestão do FDCA}

O fundo da criança e do adolescente está vinculado ao conselho dos direitos, que é o órgão responsável por estabelecer os critérios gerais de aplicação e fiscalização dos recursos. Ao incorporar a participação da sociedade civil no poder decisório, o conselho contribui para a formação de um espaço público no qual a questão da democratização das políticas sociais está em foco.

Uma conta corrente exclusiva deve ser criada após a regulamentação do fundo. Ela será gerida (movimentação dos recursos, aplicação financeira, elaboração de balanços, acompanhamento do saldo etc.) pelo órgão do Executivo ao qual o fundo está vinculado, embora as decisões quanto à aplicação dos recursos sejam da competência do conselho dos direitos. Dois importantes aspectos da gestão do FDCA são:

- gestão política - o destino dos recursos é decidido pelo conselho dos direitos, que, com base no plano de ação, elabora o plano de aplicação com as prioridades de investimento, de acordo com as demandas no âmbito da sua atuação. O conselho é o gestor do fundo; ele decide como os recursos serão aplicados e controla a execução orçamentária;

- gestão administrativa - a administração do fundo, ou seja, a celebração de convênios, pagamento, supervisão de projetos executados e o 
A elaboração do plano de ação pelo conselho dos direitos é um dos temas tratados no Capítulo 2. controle da prestação de contas é feita pelo órgão do Executivo ao qual o fundo é vinculado. Esse órgão deve prestar contas regularmente ao conselho dos direitos sobre a execução dos projetos e a movimentação da conta bancária do fundo.

A prioridade de direcionamento dos gastos deve ser dada às políticas de atendimento a crianças e adolescentes, fundamentadas em um planejamento elaborado pelo conselho dos direitos. Esse planejamento compreende a base da atuação do conselho e é composto por quatro etapas: 1) diagnóstico local da situação da criança e do adolescente; 2) plano de ação; 3) plano de aplicação; e 4) avaliação das atividades desenvolvidas na área.

\section{FDCA e comissões temáticas}

As comissões temáticas do conselho dos direitos que mais comumente atuam sobre o fundo são as Comissões Permanentes de Orçamento (CO) e de Políticas Públicas (CPP), cujos objetivos e características foram anteriormente apresentados neste capítulo.

A CO é diretamente responsável pelo fundo, já que deve elaborar e gerir o plano de aplicação e captação dos recursos do FDCA, bem como acompanhar e controlar a aprovação e aplicação dos recursos do orçamento municipal, na área da criança e do adolescente. Os membros dessa comissão podem se reunir com a secretaria responsável pelo orçamento no município (geralmente a Secretaria de Planejamento) para discutir a liberação dos recursos para o ano.

Embora as questões relativas ao fundo estejam presentes em todas as outras comissões, já que os recursos disponíveis são para a realização de qualquer ação do conselho, cabe à CO subsidiar as discussões com o material necessário para as deliberações da plenária em relação ao FDCA.

A CPP também está relacionada ao fundo, uma vez que é da sua responsabilidade o processo de implantação dos projetos financiados por ele e a mediação entre as entidades e as Secretarias de Governo, responsáveis por acompanhar os projetos. É nessa comissão que são aprofundadas as discussões que subsidiam a elaboração das diretrizes da política municipal para crianças e adolescentes. Ela também é responsável pelo 
acompanhamento dos projetos de lei em tramitação no Legislativo local, na área da criança e do adolescente. Participa, ainda, do registro e da avaliação dos programas desenvolvidos nessa área. O monitoramento do Legislativo permite ao conselho saber se há algum crédito adicional de alteração do orçamento que retire recursos de alguma política. Essas informações possibilitam o conselho traçar uma estratégia com os parceiros para a aprovação ou não de determinados projetos de lei, tendo como foco a garantia dos direitos das crianças e dos adolescentes do município.

\section{CAPTAÇÃO DE RECURSOS NA INICIATIVA PRIVADA}

A destinação ao FDCA de contribuições deduzidas de impostos é uma das fontes de recurso prevista na legislação que o cria. As campanhas de arrecadação de recursos são incentivadas e hoje é possível verificar que empresas e entidades empresariais estão se aproximando dos conselhos dos direitos. Como exemplo, destaca-se o município de Betim, no estado de Minas Gerais, que faz campanhas anuais de captação de recursos junto à iniciativa privada. Desse modo, o conseIho conseguiu aumentar em $600 \%$ os recursos do FDCA em apenas três anos. Com isso, conseguiu lugar de destaque para as políticas da infância na agenda governamental. Atualmente, o conselho dos direitos é chamado para discutir as prioridades e os recursos do orçamento municipal com os Poderes Executivo e Legislativo.

Em geral, o conselho utiliza os recursos doados da maneira que achar conveniente, de acordo com o seu plano de ação e a deliberação da maioria dos seus membros. Uma minuta de resolução do Conanda, que esteve em consulta pública em 2008, estabelece critérios e normas para as contribuições, inclusive no que se refere à definição do destino dos recursos doados ou destinados ao fundo, a chamada "verba casada, carimbada, condicionada, ou destinada".

A minuta da resolução proíbe os contribuintes de estabelecerem quaisquer condicionantes para suas doações e/ou destinações. Isso quer dizer que ficam proibidas as doações destinadas a entidades pré-definidas, por exemplo. As empresas, ao doarem recursos ao FDCA, não podem indicar para qual Organização Não Governamental (ONG), Organização da Sociedade Civil de Interesse Público (OSCIP) ou associação os recursos devem ser destinados. Essa prática, na verdade, era um meio de as empresas privadas obterem abatimento do imposto devido pela doação ao FDCA.

Ainda assim, a minuta de resolução possibilita a verba casada nas seguintes situações:

- doações a políticas pré-definidas pelo conselho dos direitos e estabelecidas em seu plano de ação. Pode ser que alguma empresa queira ter a sua imagem 
associada ao combate à violência sexual de crianças e adolescentes, por exemplo. Ao doar os recursos, a empresa define que esse montante deve ser aplicado em uma política específica, desde que faça parte do plano de ação do conselho;

- doações a projetos chancelados pelo conselho dos direitos: a chancela (aprovação prévia de projetos) permite a captação de recursos ao FDCA pelas instituições proponentes para o financiamento de seu respectivo projeto.

A minuta de resolução ainda permite ao conselho reservar entre $10 \%$ e $30 \%$ dos recursos destinados ao FDCA para livre deliberação, desde que essa reserva seja aplicada em ações prioritárias da política de promoção, proteção, defesa e atendimento dos direitos da criança e do adolescente, sob deliberação do conselho.

Relembramos que a minuta de resolução do Conanda representa um posicionamento institucional sobre esse tipo de financiamento. Os parâmetros indicados por ela devem ser adotados pelos conselhos dos direitos estaduais, distritais e municipais. Participe!

O texto deste capítulo visa a instrumentalizar você, conselheiro dos direitos ou conselheiro tutelar, em sua função de auxiliar a elaboração, a fiscalização e a avaliação da qualidade das políticas públicas sociais para a infância e adolescência em seu município/localidade. É essencial que você e os demais conselheiros possam identificar oportunidades de participação e discutir estratégias políticas para priorizar a criança e o adolescente na agenda governamental, identificando potenciais parceiros em sua atuação política no Legislativo, no Executivo e na própria sociedade civil.

Conforme discutido, uma atuação qualificada dos conselhos dos direitos e tutelares no orçamento público garante políticas públicas mais eficazes na garantia dos direitos das crianças e dos adolescentes. A pontencialidade da atuação dos conselhos, por sua vez, depende da qualidade da articulação local. Portanto, participe e seja um exemplo de atuação política para os outros conselhos no Brasil. 


\section{Leituras complementares sugeridas}

AVRITZER, L. Sociedade civil e democratização. Belo Horizonte: Del Rey, 1994.

BARRETO, M. Lugar de criança é no orçamento. ECA em Revista, n. 5, 1996.

CINTRA, J.C. Fundos municipais dos direitos da criança e do adolescente. In: Seminário A gestão do Fundo Municipal dos Direitos da Criança e do Adolescente - um modelo para São Paulo, São Paulo, 2002.

CUNHA, J.R. Orçamento público e Fundo da Infância e Adolescência. In: DINIZ, A.; CUNHA, J. R. (orgs.). Visualizando a política de atendimento à criança e ao adolescente. Rio de Janeiro: Fundação Centro de Defesa dos Direitos Humanos Bento Rubião; KroPart editores, 1997.

DAGNINO, E. (org.). Sociedade civil e espaços públicos no Brasil. São Paulo: Paz e Terra, 2002.

PRANKE, C. Crianças e adolescentes: novos sujeitos de direitos. In: CARVALHO, M.C.; TEIXEIRA, A.C. (orgs.). Conselhos gestores de políticas públicas. São Paulo: Pólis, 2000.

SADECK, F. et al. De olho no orçamento criança: atuando para priorizar a criança e o adolescente no orçamento público. São Paulo: Inesc; Abrinq; Unicef, 2005.

TATAGIBA, L. Os conselhos gestores e a democratização das políticas públicas no Brasil. In: DAGNINO, E. (org.). Sociedade civil e espaços públicos no Brasil. São Paulo: Paz e Terra, 2002.

VOLPI, M. A democratização da gestão das políticas públicas para a infância e a adolescência. In: CARVALHO, M.C.; TEIXEIRA, A.C. (orgs.). Conselhos gestores de políticas públicas. São Paulo: Pólis, 2000.

\section{Referências}

BRASIL. Constituição da República Federativa do Brasil de 1988. Disponível em: <http://www.planalto.gov.br/ccivil_03/constituicao/constitui\%C3\%A7ao.htm>.

BRASIL. Lei Complementar n.101, de 4 de maio de 2000: estabelece normas de finanças públicas voltadas para a responsabilidade na gestão fiscal e dá outras providências. Disponível em: <http://www.planalto.gov.br/ccivil_03/Leis/LCP/lcp101.htm>.

BRASIL. Lei Federal n 8.069 de 13 de julho de 1990: dispõe sobre o Estatuto da criança e do adolescente e dá outras providências. Disponível em:

<http://www.planalto.gov.br/ccivil_03/LEIS/L8069.htm>.

BRASIL. Lei n. 8242, de 12 de outubro de 1991: cria o Conselho nacional dos direitos da criança e do adolescente - Conanda e dá outras providências. Disponível em: <http://www.pge.sp.gov.br/ centrodeestudos/bibliotecavirtual/dh/volume\%20i/crian\%C3\%A7alei8242.htm>. 
BRASIL. Lei n. 10.257, de 10 de julho de 2001: estabelece diretrizes gerais da política urbana e dá outras providências. Disponível em:

<http://www.planalto.gov.br/ccivil_03/leis/LEIS_2001/L10257.htm>.

BRASIL. Lei n. 4.320, de 17 de março de 1964: estatui normas gerais de Direito Financeiro para elaboração e controle dos orçamentos e balanços da União, dos Estados, dos Municípios e do Distrito Federal. Brasília, 1964.

CEATS. Centro de Empreendedorismo Social e Administração em Terceiro Setor; FIA. Fundação da Infância e Adolescência. Os bons conselhos: pesquisa "conhecendo a realidade". São Paulo: Ceats/FIA, 2007. 